九州大学学術情報リポジトリ

Kyushu University Institutional Repository

\title{
An Adaptive Modeling Technique for Instream Fish Habitat Preference of Japanese Medaka (Oryzias Latipes)
}

Fukuda, Shinj i

Graduate School of Bioresource and Bioenvironmental Sciences

Hiramatsu, Kazuaki

Faculty of Agriculture, Kyushu Unviersity

Mori, Makito

Faculty of Agriculture, Kyushu Unviersity

Shikasyo, Shiomi

Professor Emeritus of Kyushu University

https://doi.org/10.5109/4649

出版情報：九州大学大学院農学研究院紀要. 50 (2)，pp.363-373，2005-10-01. Faculty of Agriculture, Kyushu University

バージョン：

権利関係 : 


\title{
An Adaptive Modeling Technique for Instream Fish Habitat Preference of Japanese Medaka (Oryzias latipes)
}

\author{
Shinji FUKUDA ${ }^{1 *}$, Kazuaki HIRAMATSU, Makito MORI \\ and Shiomi SHIKASHO ${ }^{2}$
}

\author{
Laboratory of Drainage and Water Environment, Division of Regional Environment Science, \\ Department of Bioproduction Environmental Sciences, Faculty of Agriculture, \\ Kyushu University Fukuoka 812-8581, Japan \\ (Received June 30, 2005 and accepted July 26, 2005)
}

\begin{abstract}
It is widely known that habitat selections of riverine fish differ within and between rivers. In our past study, the preference intensity of Japanese Medaka (Oryzias latipes) to three environmental factors of water depth, current velocity and cover ratio was quantified on laboratory open-channel experiments for developing a general habitat preference model. A simplified fuzzy reasoning method was introduced in consideration of essential vagueness of fish behaviors. The fuzzy preference intensity model was then optimally searched with a simple genetic algorithm and was successfully verified by both laboratory water tank experiments and on-the-spot examination. The results indicated that this general model showed agreement between predicted and observed spatial distribution of target fish, but the habitat preference models are still desired to be developed through field studies. In this study, we propose an adaptive modeling technique for instream fish habitat preference by conjugating the fish preference intensity model developed in laboratory experiments. The adaptive prediction model was also determined by simple genetic algorithm, which enabled us to model the habitat preference of instream resident fish even with insufficient data.
\end{abstract}

\section{INTRODUCTION}

The demand for ecological restoration is generally recognized, and several guidelines for assessing environmental changes have been proposed (Hayes and Jowett, 1994; Lamouroux and Capra, 2002; Lamouroux and Souchon, 2002). The microhabitat models of each method are now facing the problem of transferability of fish habitat selection. In the past, human activities such as urbanization, reclamation and settlement reduced both availability and quality of fish habitat. Agricultural canals also have increasingly altered into artificial flume with a view to water management, although these canals play an important role for living things as spawning and nursery sites. Many species reside in habitats surrounding paddy fields during their life cycles. For example, loaches (Misgurnus anguillicaudatus) winter in permanent creeks, enter paddy fields via temporary creeks, and spawn and reproduce in paddy fields (Tanaka, 1999). Hata (2002) evaluated the important role of agricultural water channels and paddy fields in the life of

\footnotetext{
1 Laboratory of Drainage and Water Environment, Division of Regional Environment Science, Department of Bioproduction Environmental Sciences, Graduate School of Bioresource and Bioenvironmental Sciences, Kyushu University

2 Professor Emeritus of Kyushu University

* Corresponding author (E-mail: shinji-fkd@bpes.kyushu-u.ac.jp)
} 
fish: three-spined stickleback (Gasterosteus aculeatus aculeatus), carp (Cyprinus carpio), Prussian carp (Carassius carassius subsp.), catfish (Silurus asotus), Japanese Medaka (Oryzias latipes), loach and Miyako-tanago (Tanakia tanago). With understanding their value in nature, applicable techniques for ecological restoration are urgently needed in waterfront development. Several models, e. g., IFIM (Instream Flow Incremental Methodology: Stalnaker et al., 1995), have been proposed and applied for assessing the impact of human activities (e. g., Reiser et al., 1989; Van Winkle et al., 1998; Spence and Hickley, 2000; Holms et al., 2001; Lamouroux and Capra, 2002; Lamouroux and Souchon, 2002), but, in the application, it was found that fish had site-specificity in their habitat selection.

In the past study, we quantified the preference intensity of Japanese Medaka to three environmental factors: water depth, current velocity, and cover, using laboratory open channel experiment for the purpose of development of a general habitat preference model (Hiramatsu and Shikasho, 2002). A simplified fuzzy reasoning was introduced in order to take essential vagueness of fish behavior into consideration (Hiramatsu et al., 2003). We utilized a simple genetic algorithm (Hiramatsu and Shikasho, 2004) to search for an optimal model structure, and then the fuzzy preference intensity model was constructed. The result showed a sound agreement between predicted and observed fish distribution of Japanese Medaka in both the laboratory water tank experiment and on-the-spot examination. The site-specificity of microhabitat preferences of fish, however, was implied in the verification, which induced us to develop the habitat preference model in the field studies.

From the observation in the past study (Hiramatsu et al., 2003), we have found it difficult to obtain data sufficient to construct fuzzy preference intensity models in agricultural canals. This difficulty may result from its even distribution of physical environments of water depth and current velocity. The present study proposes an adaptive modeling technique for fish habitat preference of Japanese Medaka by conjugating the fuzzy preference intensity model developed in laboratory experiments. An artificial intelligence technique of simple genetic algorithm was introduced to develop the fuzzy preference intensity model even with insufficient data of on-the-spot examination.

\section{MATERIALS AND METHODS}

\section{Study site}

The agricultural canal for the study site is located in Kurume city, Fukuoka, Japan (Fig. 1). The chosen canal has a low gradient, almost unlined and is used as a dual-purpose canal. It is originating in the spring so that water runs throughout the year and thus fish population of Japanese Medaka is supported during the non-irrigation period in the canal. The observation point is located at midpoint in the canal, whose length is about $50 \mathrm{~m}$ and width ranging from $1.6 \mathrm{~m}$ to $2.0 \mathrm{~m}$. A concrete agricultural facility is located about $31 \mathrm{~m}$ up from the downstream end. Topminnow (Gambusia affinis), a competitive species to Japanese Medaka, is not found in the canal.

\section{Data sampling}

During the irrigation period, agricultural canals are stemmed by weirs; almost all the 
Hydrophyte-free Submerged vegetation

(a)

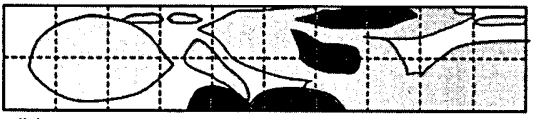

(b)

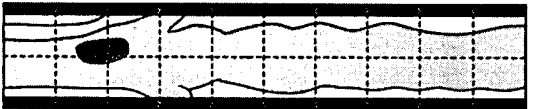

(c)

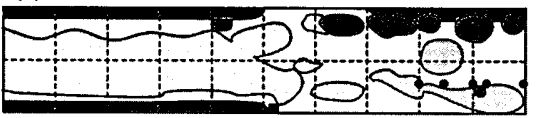

(d)

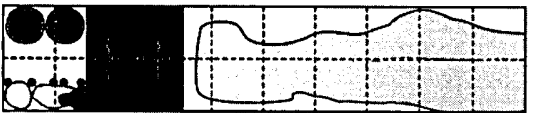

(e)

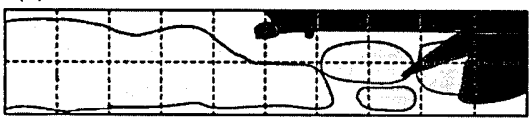

Emergent vegetation Emersed area

(a)

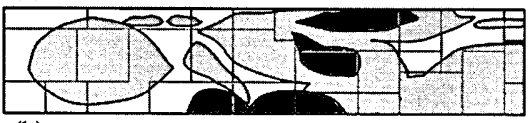

(b)

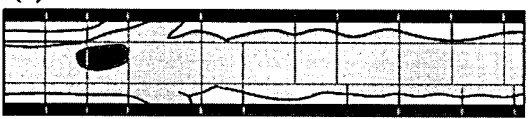

(c)

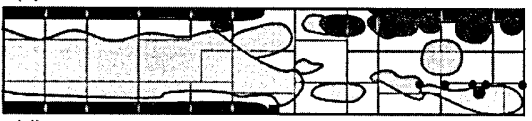

(d)

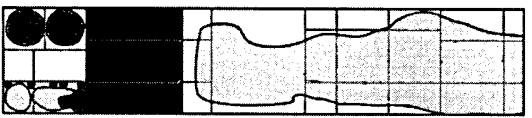

(e)

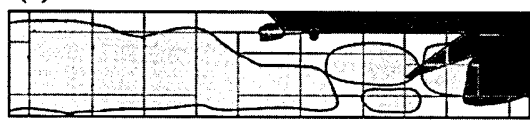

Fig. 1. Schematic of overview (left) and water bodies (right) of the study site.

area has similar habitat characteristics such as deep water and low current velocity. For this reason, it becomes difficult to develop habitat preference models. Multiplicity in distribution of physical environments is necessary for model construction, so the on-the-spot examination was carried out during the non-irrigation period. The census was taken on a sunny day, November 5 . Mean water temperature was $17.5^{\circ} \mathrm{C}$ $\left(16.1-18.5^{\circ} \mathrm{C}\right)$. First, we observed fish distribution (11:00-13:30) and then measured spatial habitat characteristics.

\section{Fish observation}

We observed fish from the upstream end toward downstream so as to minimize fish disturbance. The distribution of Japanese Medaka was counted by sight every five fish, according to previous studies. Iwamatsu (1997) pointed out that attractive fish schools of Medaka increased proportionately with the number of fish up to five. Kanda and Itazawa (1986) represented that grouped Medaka showed more stability in locomotor activity and less consumption of oxygen compared to individual fish. A series of fish observations was repeated eight times, and the results were averaged to avoid observation variance.

\section{Spatial habitat characteristics}

Spatial habitat characteristics of water depth, current velocity, and cover ratio were measured to quantify the habitat preference of Japanese Medaka. Water depth was sur- 
veyed with a stainless steel ruler, and current velocity with a portable propeller current meter (KENEK V-303) at intervals of $1 \mathrm{~m}$. In order to determine similarity in the physical environmental factor, the study site was divided into water bodies by measuring water depth and current velocity. Fish population density was calculated from the obtained information.

We estimated cover ratio from the schematic of water bodies (Fig. 1) according to the following definition.

\section{Definition of cover ratio}

The definition of cover ratio follows, with reference to the authors' experiment (Hiramatsu et al., 2003):

$$
\text { Cover ratio (\%) }=\mathrm{LR}-\operatorname{cover}(\%)+\mathrm{TB}-\operatorname{cover}(\%)
$$

where "LR" is abbreviation of left and right, and "TB" of top and bottom. Both LR-cover and TB-cover becomes up to $50 \%$. LR-cover is valued the maximum of $50 \%$ when four lateral sides (backward, forward, left and right which is equally evaluated at $12.5 \%$ each) of water body are covered with water's edge or emergent vegetation. TB-cover consists of upper and bottom cover of $25 \%$ each. We give $25 \%$ to TB-cover for streambed since we do not consider upper cover into the calculation for its obstruction to fish observation. Therefore, cover ratio is estimated to be the maximum of $75 \%$.

\section{Existing fuzzy preference intensity model}

The preference intensity model (subsequently called source model) was developed upon two laboratory open channel experiments. A single-factor experiment was undertaken to quantify preference intensity for a single environmental factor, and a composite-factor experiment to relate preference intensities between three environmental factors. A simplified fuzzy reasoning was introduced to explicitly take the essential vagueness of fish behavior. Singletons for the consequence part of fuzzy if-then rule were optimally searched by a simple genetic algorithm (Table 1). The source model was thus constructed and then successfully verified by both laboratory water tank experiment and on-the-spot examination.

Table 1. Consequence parts for the fuzzy preference intensity models developed using the laboratory open channel experiment and on-the-spot examination data, respectively.

\begin{tabular}{|c|c|c|c|c|c|c|c|}
\hline \multirow{2}{*}{$\begin{array}{l}\text { Laboratory } \\
\text { experiment }\end{array}$} & \multirow{2}{*}{ Weight } & \multicolumn{6}{|c|}{ Singletons for consequence part } \\
\hline & & 1 & 2 & 3 & 4 & 5 & 6 \\
\hline Depth & 0.46 & - & 0.0952 & 0.1429 & 0.2698 & 1 & 0.6984 \\
\hline Velocity & 1 & 0.5873 & 1 & 0.9365 & 0.3175 & 0.1429 & 0.0635 \\
\hline Cover & 0.49 & 0.1270 & 0.2222 & 1 & - & - & - \\
\hline \multirow{2}{*}{$5-N o v-04$} & \multirow{2}{*}{ Weight } & \multicolumn{6}{|c|}{ Singletons for consequence part } \\
\hline & & 1 & 2 & 3 & 4 & 5 & 6 \\
\hline Depth & 0.46 & 0 & 0.0159 & 0.0159 & 0.2540 & 0.4286 & 1 \\
\hline Velocity & 1 & 1 & 0.5079 & 0.1746 & 0 & 0 & 0 \\
\hline Cover & 0.49 & 0 & 0.2222 & 1 & - & - & - \\
\hline
\end{tabular}




\section{Adaptive fuzzy preference intensity model}

The present chapter describes how adaptive modeling technique works with insufficient data. The concept of the adaptive fuzzy preference intensity model is almost the same as the source model, while several improvements have been added. The procedure is as follows. First, the premise part for the fuzzy if-then rule is defined (Fig. 2). In the present study, the premise part for the water depth has changed with a view to take the ecological factor into consideration for the model. The fuzzy set for the depth of $2 \mathrm{~cm}$ has been added. The adjoined membership function represents a shallower limit for inhabitancy of Japanese Medaka so that the singleton corresponding to that fuzzy set is assumed to be zero. Morishita and Morishita (1997) pointed out that fish require a depth of at least three-fold body length in order to inhabit in a stream, which supports the above ecological hypothesis. Second, determinable fuzzy relations are searched because not all the fuzzy relations can be determined in the case of shortage of data. To solve the problem of insufficiency, fuzzy relations of the source model are substituted into the adaptive model instead of the indeterminable one. Third, the singletons for the consequence part are determined by the use of the simple genetic algorithm. In the optimization, the codes for singletons are given six bits each for the singletons. The fitness function is defined by the multiplicative inverse of square error between observed and predicted fish population density ( $\rho_{0, i}$ and $\rho_{\mathrm{c}, i}$ respectively) as follows. To start with, we composite preference intensities to a single environmental factor of water depth, current velocity, and cover ratio using the Sekine's expression (Sekine et al., 1997),

(a) Water depth
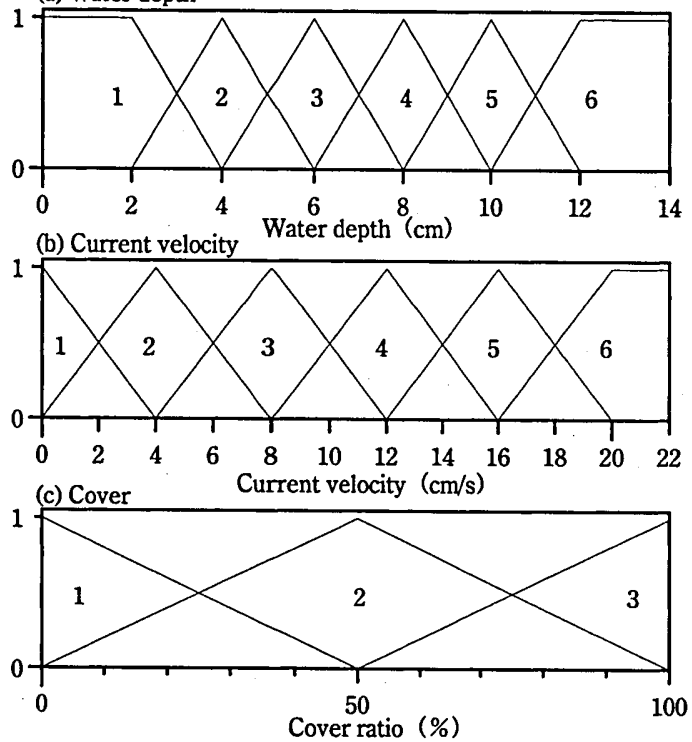

Fig. 2. Premise part for the fuzzy preference intensity model. 


$$
P_{i}=\prod\left(P_{i, j}\right)^{\frac{W_{j}}{W_{\max }}}
$$

where $P_{i}$ denotes preference intensity for the $i$ th water body, $i(=1,2, \ldots, n)$ the number of water bodies, $W_{j}$ the weight of $P_{i, j}$, and $j(=$ depth, velocity and cover) environmental factor. This equation (2) is newly introduced in the model so that the weight $W_{j}$ has been recalculated (Table 1). Subsequently, fish population density $\rho_{\mathrm{c}, i}$ is predicted with preference intensity and following equation

$$
\rho_{\mathrm{c}, i}=\left(P_{i} / \sum_{i=1}^{n} P_{i}\right) \sum_{i=1}^{n} \rho_{0, i}
$$

where $\rho_{\mathrm{o}, i}$ is observed fish population density. Thereupon, the fitness function $F_{t}$ is given as

$$
F_{\imath}=1 / \sum_{i=1}^{n}\left(\rho_{0, i}-\rho_{\mathrm{c}, i}\right)^{2} .
$$

Altogether with the above calculation, the computation is conducted under the following conditions: at least one of the singletons for each environmental factor becomes the maximum of unity, and the singletons subsequent from the maximum singleton have values with the tendency of steady, decreasing, or increasing. In the case that the condition cannot be satisfied, the penalty of $10^{-3}$ is forcedly given as fitness. It is widely known that fish have an optima or threshold in habitat preference, which permits us to introduce these calculative restrictions. Finally, the fuzzy preference intensity model is constructed and verified with the on-the-spot examination data using Spearman's rank correlation test.

\section{RESULTS}

The result of the on-the-spot examination is shown in Fig. 3. Water depth ranges from $3 \mathrm{~cm}$ to $57 \mathrm{~cm}$, current velocity from $1.5 \mathrm{~cm} / \mathrm{s}$ to $31.6 \mathrm{~cm} / \mathrm{s}$, and cover ratio from $25 \%$ to $50 \%$, which reveals the sufficiency in both water depth and current velocity for the model construction, and its lack in cover ratio. Therefore, the singleton for the $100 \%$ of cover ratio has been substituted from the source model into the adaptive model. The optimally searched consequence part is shown in Fig. 4, and preference intensity distribution calculated by the model is in Fig. 5. Maximum habitat preference is found from calculation to be over $12 \mathrm{~cm}$ of water depth, $0 \mathrm{~cm} / \mathrm{s}$ of current velocity, and $100 \%$ of cover ratio. The preference for water depth and cover ratio increases in keeping with environmental value, but for current velocity decreases. Fish population density calculated using the fuzzy preference intensity model and equation (3) is shown in Fig. 6 in comparison to observed data of the on-the-spot examination. The adaptive model explained fish distribution well. The predicted and observed fish population data correlated significantly $\left(r_{\mathrm{s}}=0.668, \mathrm{p}<0.001\right)$. The square error between predicted and observed fish population density decreases from 23.33 to 18.42 (individuals per $\mathrm{m}^{2}$ ). 


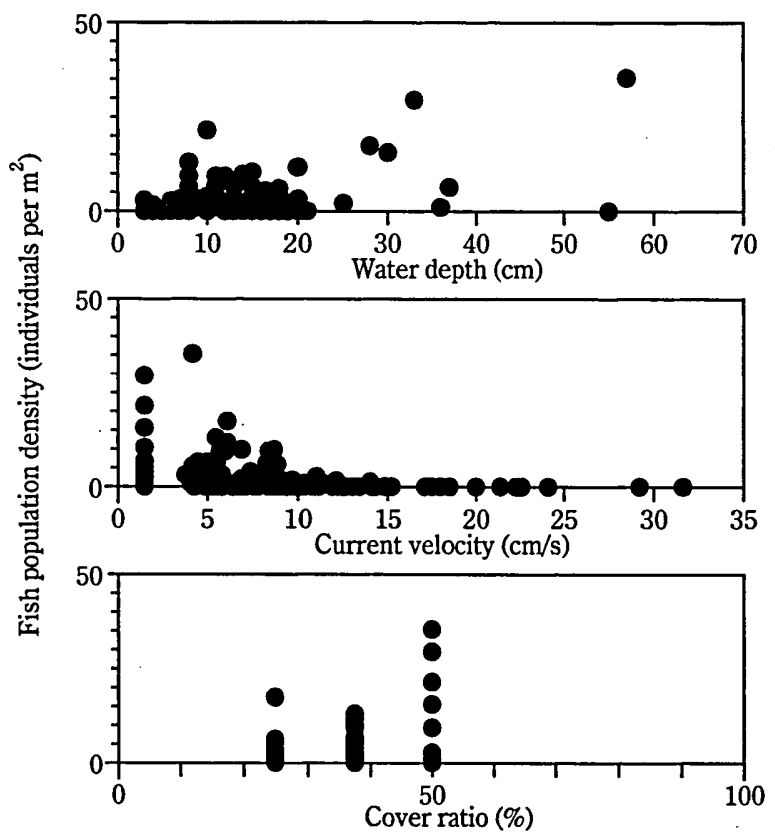

Fig. 3. Fish population density and physical habitat characteristics.
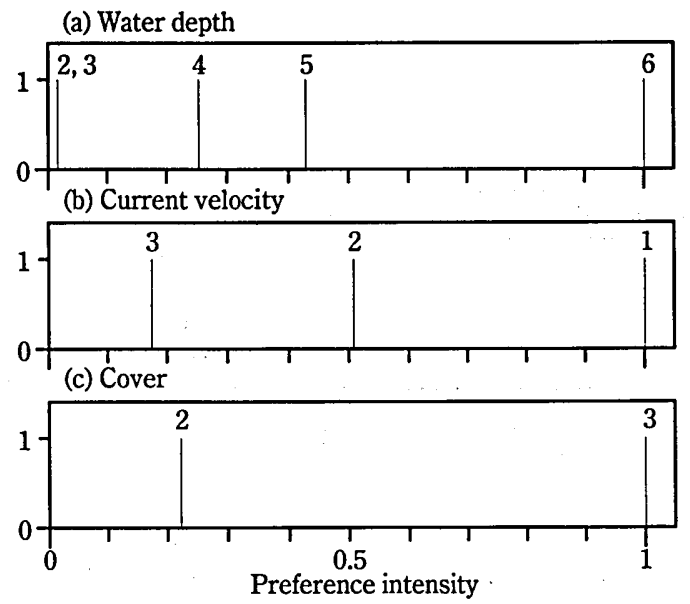

Fig. 4. Consequence part for the fuzzy preference intensity model developed using on-the-spot examination data. 
(a) Water depth

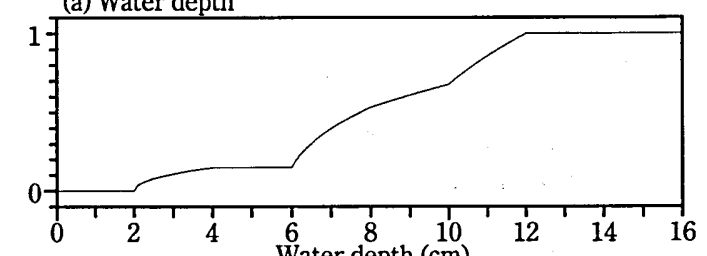

(b) Current velocity

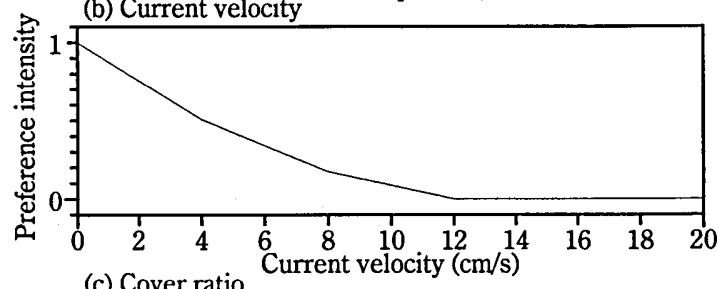

(c) Cover ratio

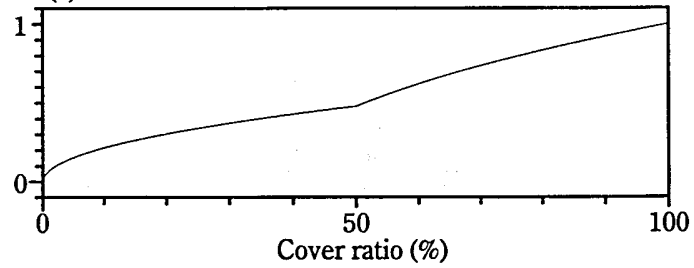

Fig. 5. Preference intensity distribution calculated by the fuzzy preference intensity model.

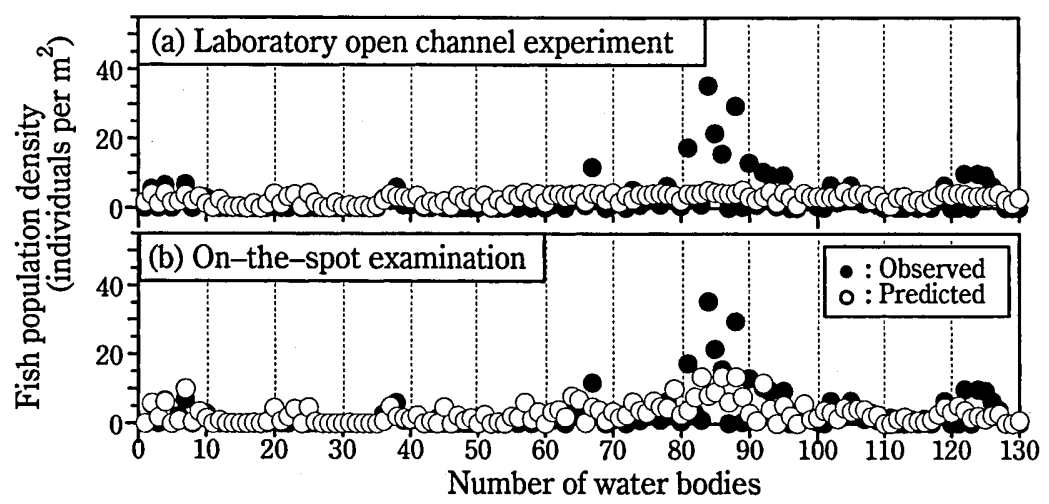

Fig. 6. Comparison between observed and predicted fish population density calculated by fuzzy preference intensity models developed using the laboratory open channel experiment and on-the-spot examination data, respectively. 


\section{DISCUSSION}

The result of the field examination (Fig. 3) indicates the avoidance in depths shallower than $8 \mathrm{~cm}$, velocity faster than $10 \mathrm{~cm} / \mathrm{s}$, and less than $50 \%$ of cover. The obtained fuzzy preference intensity model describes a similar tendency in the prediction (Figs. 4, 5 and Table 1). The preference for deeper water is generally recognized as a shelter in a stream channel that provides aquatic organisms protection from avian or terrestrial predators in the force of visual isolation and so on (Power, 1985; Stalnaker et al., 1995). Although the Japanese Medaka is often found swimming near the surface in a stream, Yokota and Oishi (1992) reported that Medaka, in their experiment under natural condition, showed diurnal activity at the lower layer in autumn and winter, which supports the result of our observation. Slower velocity is preferred among fish larvae because of their limitation in swimming ability. In general, swimming ability of stream fish is assumed to increase in correlation to body length. Vincent (1960) demonstrated that wild-stock fish had greater stamina than domesticated fish. The major difference in consequence part between the two models (Table 1) can be explained as a difference in swimming ability between wild and domestic. Some riverine fish change their habitat from lower to faster velocity according to increased body length (Suzuki, 1998). Adult Medaka becomes only $20 \mathrm{~mm}$ to $30 \mathrm{~mm}$ of body length, and, hence, dwells in slow flowing areas. The present result shows preference for larger cover ratio. In other microhabitat models (e. g., Bovee et al., 1998), definition of cover differs in each model while we defined the term consistent with the laboratory open channel experiment. We focused on the existence of water's edge, emergent vegetation and a dike surrounding the body of water. This includes the concept of distance from shore (Wolter and Bischoff, 2001) and showed similar results. Medaka preferred the near-the-shoreline habitats rather than mid-channel.

From the comparison between observed and predicted fish population density (Fig. 6 ), it is apparent that the present modeling technique can be widely applicable, and gives us a better prediction than the model developed using only laboratory experiments. The prediction becomes more precise, and the fish distribution was well represented. For site-specific environmental condition including fish density, stream productivity, physical habitat characteristics, and fish community structure (Johnson, 2002), the microhabitat models should be developed through field studies. The present study describes an adaptive modeling technique that can quantify fish habitat preference in a definite procedure. Further application of the present model to both different rivers and seasons will be necessary for validation and for assessment.

\section{ACKNOWLEDGEMENTS}

The authors gratefully thank Mr. Katsuichiro Abe, a graduate student at the Laboratory of Drainage and Water Environments, Kyushu University, for his extensive assistance in the field survey.

\section{REFERENCES}

Bovee, K. D., Lamb, B. L., Bartholow, J. M., Stalnaker, C. B., Taylor, J. and Henriksen, J. 1998 Stream 
habitat analysis using the instream flow incremental methodology. U. S. Geological Survey, Biological Resources Division Information and Technology Report. USGS/BRD-1998-0004

Hata, K. 2002 Perspectives for Fish Protection in Japanese Paddy Field Irrigation Systems. Japan Agricultural Research Quarterly, 36(4): 211-218

Hayes, J. W. and Jowett, I. G. 1994 Microhabitat Models of Large Drift-Feeding Brown Trout in Three New Zealand Rivers. North American Journal of Fisheries Management, 14: 710-725

Hiramatsu, K., Fukuda, S. and Shikasho, S. 2003 Mathematical Modeling of Preference Intensity of Japanese Medaka for Instream Water Environment using Fuzzy Inference. Transactions of the Japanese Society of Irrigation, Drainage and Reclamation Engineering, 228: 65-72 (in Japanese with English abstract)

Hiramatsu, K. and Shikasho, S. 2002 Mathematical Modeling of Preference Intensity of Japanese Medaka (Oryzias latipes) for Environmental Factors in Streamflow. Journal of the Faculty of Agriculture, Kyushu University, 47(1): 109-127

Hiramatsu, K. and Shikasho, S. 2004 GA-based model optimization for Preference Intensity of Japanese Medaka Fish (Oryzias latipes) to streamflow environments. Paddy and Water Environment, 2: 135-143

Holm, C. F., Armstrong, J. D. and Gilvear, D. J. 2001 Investigating a major assumption of predictive instream habitat models: is water velocity preference of juvenile Atlantic salmon independent of discharge?. Journal of Fish Biology, 59: 1653-1666

Iwamatsu, T. 1997 The Integrated Book for the Biology of the Medaka. University Education Press, Okayama (Japan) (in Japanese)

Johnson, J. B. 2002 Divergent life histories among populations of the fish Brachyrhaphis rhabdophora: detecting putative agents of selection by candidate model analysis. OIKOS, 96: 82-91

Kanda, T. and Itazawa, Y. 1986 Grouped Effect on Locomotor Activity of Larvae and Juveniles of Medaka, Science Bulletin of the Faculty of Agriculture Kyushu University, 40(4): 235-238 (in Japanese with English abstract)

Lamouroux, N. and Capra, H. 2002 Simple prediction of instream habitat model outputs for target fish populations. Freshwater Biology, 47: 1543-1556

Lamouroux, N. and Souchon, Y. 2002 Simple prediction of instream habitat model outputs for fish habitat guilds in large streams. Freshwater Biology, 47: 1531-1542

Morishita, I. and Morishita, Y. 1997 Kyosei no shizen-gaku, Stream organisms in Japan: how they are affected by Japanese culture and how they express ecological health. Sankaido publishing Co., LTD., Tokyo (Japan). pp. 38-39 (in Japanese with English description)

Power, M. E. 1984 Depth distributions of armored catfish: predator induced resource avoidance?. Ecology, 65: 523-528

Reiser, D. W., Wesche, T. A. and Estes, C. 1989 Status of Instream Flow Legislation and Practices in North America. Fisheries, 14(2): 22-29

Sekine, M., Imai, T. and Ukita, M. 1997 A model of fish distribution in rivers according to their preference for environmental factors. Ecological Modelling, 104: 215-230

Spence, R. and Hickley, P. 2000 The use of PHABSIM in the management of water resources and fisheries in England and Wales. Ecological Engineering, 16: 153-158

Stalnaker, C., Berton, L. L., Henriksen, J., Bovee, K. and Bartholow, J. 1995 The Instream Flow Incremental Methodology: A Primer for IFIM. Biological Report 29, National Biological Service, US Department of the Interior, 1-45

Suzuki, O. 1998 Relationship between Standard Length and Preferred Water Velocity on Freshwater Fish for Natural Diverse River Construction Methods. Journal of Hydraulic, Coastal and Environmental Engineering, 593/I-43: 21-29 (in Japanese with English abstract)

Tanaka, M. 1999 Influence of different aquatic habitats on distribution and population density of Misgurnus anguillicaudatus in paddy fields. Japanese Journal of Ichthyology, 46(2): 75-81 (in Japanese with English abstract)

Van Winkle, W., Jager, H. I., Railsback, S. F., Holcomb, B. D., Studley, T. K. and Baldrige, J. E. 1998 Individual-based model of sympatric populations of brown and rainbow trout for instream flow assessment: model description and calibration. Ecological Modeling, 110: 175-207

Wolter, C. and Bischoff, A. 2001 Seasonal changes of fish diversity in the main channel of the large lowland River Oder. Regulated Rivers: Research \& Management, 17: 595-608 
Vincent R. E. 1960 Some Influences of Domestication upon Three Stocks of Brook Trout (Salvelinus fontinalis Mitchill). Transactions of the American Fisheries Society, 89(1): 35-52

Yokota, T. and Oishi, T. 1992 Seasonal change in locomotor activity rhythm of medaka, Oryzias latipes. International Jourmal of Biometeorology, 36(1): 39-44 